\title{
An approach to energy management: A case study of a medium scale printing press in Lagos, Nigeria
}

\author{
Sogo Mayokun Abolarin ", Manasseh Babale Shitta, Chimaobi Daniel Nna, \\ Charles Asirra Eguma, Allwell Osariere Kedo, Abdulmutalib Yussuff, \\ Oluwabori Ayodeji Babatunde, Babatunde Olubusayo Onafeso, Oluwole Adegbenro
}

National Centre for Energy Efficiency and Conservation, [Energy Commission of Nigeria], University of Lagos, Nigeria

Email address:

sogoabolarin@gmail.com (S. M. Abolarin)

\section{To cite this article:}

Sogo Mayokun Abolarin, Manasseh Babale Shitta, Chimaobi Daniel Nna, Charles Asirra Eguma, Allwell OsariereKedo, Abdulmutalib Yussuff, Oluwabori Ayodeji Babatunde, Babatunde Olubusayo Onafeso, Oluwole Adegbenro. An Approach to Energy Management: A Case Study of a Medium Scale Printing Press in Lagos, Nigeria. International Journal of Energy and Power Engineering.

Vol. 3, No. 1, 2014, pp. 7-14. doi: 10.11648/j.ijepe.20140301.12

\begin{abstract}
This paper investigates Energy Management Opportunities for reducing energy wastes in a medium scale manufacturing industry's production processes. The energy information on electricity and diesel consumption for the year 2011 was obtained to complement data collected from walk-through and comprehensive audits. An estimated 125,181kWh of electricity and 33,415 litres of diesel representing $32 \%$ electricity and $68 \%$ diesel costs, which amounts to $\$ 44,562.50$ were consumed for the period. Energy efficiency and conservation opportunities identified to promote energy savings, cost savings and environmental sustainability are: the replacing of inefficient drive belts on large motors with efficient cog belts, monitoring electrical loads to reduce peak demand, turning off equipment when not in use, replacing inefficient lamps with energy-saving lamps and installing bank of capacitors to increase power factor. The opportunities reveal a net saving of $\$ 6,231.18$, which is about $14 \%$ of the company's annual energy cost.
\end{abstract}

Keywords: Energy Management Opportunities, Energy Audit, Energy Efficiency and Conservation, Energy Consumption

\section{Introduction}

Energy consumption is increasing worldwide as a result of increasing population, quest for better standards of living and emphasis on large-scale industrialization in developing countries, thus sustaining positive economic growth rates [1-2]. Precise energy projections provide the foundation for daily operations, market planning, and budgeting and risk management [3]. For this reason, the efficient use of energy is a worthy adventure.

Profit motive is the driver of efficiency in industry. An industry is set up to produce goods and services at a viable economic level in order to yield good returns on investment. If goods can be produced cheaply, the better are the chances of making huge profits at the expense of other competitors.

Goods can be produced at a reduced cost if the various inputs required in production namely energy, raw materials and labor can be obtained cheaply and maximized. Energy is a chief determinant of production cost and the vagaries in its cost may eventually determine the profitability or folding up of an industry. It is therefore important that a serious energy manager explores all and every means of reducing the energy input[4].

Electricity is one of the key elements of any economy, industrialized society or country. However, many companies especially in developing countries continue to groan under the pains of inadequate electricity supply to drive productive processes. The adoption and use of appropriate technology systems as means to optimize energy use is becoming more pertinent to industry and will help maximize energy resource inputs in industrial manufacturing processes[5-11].

In Nigeria energy is supplied to industries from both the electricity utility companies and in-house diesel generating sets. There is high dependency on the latter as a result of inadequate and intermittent supply from the utility company. Unfortunately, this has been found to be very expensive and environmentally unfriendly. The consumption of energy in 
the form of fossil fuel combustion is the largest single contributor to anthropogenic (human causes) greenhouse gas emissions in the world. The emission of these gases into the atmosphere has resulted in what is now generally known as climate change or global warming. The large industries in Nigeria are energy intensive and depend on low and high pour fuel oils. These industries are now within big cities and highly developed urban areas. For the small towns and villages, the bulk of the small - scale industries are operated on diesel generators for bakeries, small - scale steel works, small - scale ceramic/pottery works etc.[12-17].

The Energy Commission of Nigeria 2009reports the energy demand within different sectors of Nigeria economy. The residential sector accounts for $65 \%$ of the total customer's connection to the national grid, followed by the commercial sector $(20 \%)$, industrial $(10 \%)$ and others $(5 \%)$. The residential sector is also the largest (electricity) consumer in Nigeria, accounting for $64 \%$; followed by the commercial $(20 \%)$; industrial sector consumes only $10 \%$; while 5\% goes for export and tertiary, health and educational institutions consume just $1 \%$. The industrial sector, the third largest energy consumer in the Nigeria economy needs adequate energy in order to increase production. Presently, only $40 \%$ of the nation's energy needs is met by the national grid, with the rest met by private generation. Nigeria like many other developing countries, in order to meet its energy needs pay more attention to issues relating to generation, transmission and distribution of electricity with little or no attention paid to the ways in which energy is used [13].

According to an Energy Commission of Nigeria's report on the study for the development of energy balance for Nigeria (2009), the industrial sector's consumption rose from 1870.40 to $3937.62 \mathrm{GWh}$ of electricity from 2000 to 2006. In 2008, the manufacturing sector consumed 353 million tonnes of oil equivalent of electricity. This increase in energy consumption may be traceable to the unchecked inefficient practices of the consumers that have been lingering for a long time and the energy demand at that time due to continued rise in population. Energy Efficiency practices are presently being introduced to Nigeria; the country with highest population in Africa of about 160 million but inadequate power generation, to increase energy access and improve economy [13]. The government on its part has proposed increase in power supply from the present $5000 \mathrm{MW}$ to $10,000 \mathrm{MW}$ by the end of 2014 and $20,000 \mathrm{MW}$ by 2016 through the building independent power plants in conjunction with private sector across the country. This effort being seen as laudable should be supported with advocacy that will ensure energy sustainability, which is one of the reasons for this paper.

Lagos State is the industrial and economic nerve Centre of Nigeria. The majority of the industries within the state still rely on machinery and equipment which are considered inefficient in terms of energy use. These industries operate high energy demanding processes and are overburdened by increasing energy needs and high overhead cost which outstrip productivity benefits and are not economically viable. This has led to reduced output, declining profits, staff redundancies and eventual closure of companies[18-25].

An attempt to identify energy management opportunities and propose measures to reduce energy demand from appliances and machinery, is a necessary action that should be supported by industrial managers, to help find solution to the increasing energy burden and maximize inputs from energy resources. The adoption and use of energy management programs will help to quickly understand plants' energy use, identify plants' major energy-consuming equipment, provide an overview of plants' energy purchases, represent a good first step in identifying potential savings of energy and money and describe typical next steps to ensure savings [26-27]. Therefore, energy efficient technologies (appliances and machineries) will significantly reduce energy costs and enhance productivity benefits[28-29].

Energy is required in industry for lighting, in electric motors (as prime movers), in boilers (for raising steam and hot water), in compressors (for producing compressed air used in pneumatic tools), in heating, ventilation and air conditioning systems, in internal transport and cleaning amongst others. In each of the machineries mentioned, great potential exists for energy savings. An energy consumption assessment carried out in a typical indigenous pulp and paper mill industry in Lagos shows that electric motors, boilers and compressors which carry the highest percentage of the energy consumption of about $99.51 \%$, followed by Heating, Ventilation and Air Conditioning with $0.36 \%$ and the remaining is for lighting.

Energy management should be considered at the point when decisions about the sources of energy appropriate for different areas in the industry are to be made[30-31]. Nigeria is endowed with conventional and alternative energy sources and it is quite possible to select an energy source appropriate to satisfy particular work requirements. An industry should, after considering factors such as applicable regulation, concern for the environment etc select whichever source of energy gives relief to its energy burden[14,32-33]. Considerable benefits are derived when energy efficiency and conservation best practices are adopted to increase production efficiency and environmental sustainability[34-36].

Conscious of the role energy management plays in maximizing energy use in industry, the National Centre for Energy Efficiency and Conservation (NCEEC), Lagos, carried out a walk-through audit and detailed energy analysis for a printing company in Lagos to identify potentials for energy saving and possible ways to reduce energy wastage. The analysis provided a self-assessment method for the industry to improve its operations, optimize energy use and reduce production costs through adoption and implementation of energy efficiency and conservation measures. 


\section{Methodology}

A pre-implementation assessment visit was scheduled between the audit team and the company to seek management consent and approval. The meeting provided the audit team with first-hand information about the entire production processes and the energy streams entering the facility. The approach in this study involved walk through and comprehensive audits. The audit team inspected different units within the company including areas where production activities are carried out and the various equipment and machinery. The necessary energy data, among other information, were obtained from technical and equipment specification sheets. The electricity and diesel consumption between January 2011 and December 2011 were collected and analyzed to understand the energy consumption pattern within the industry. Energy is consumed primarily in two ways; via electricity supply from the electricity utility company in Nigeria, and diesel fuel which powers a $200 \mathrm{kVA}$ generating set. This is a standard audit approach [2, 28, 37-38].

During the walk through audit, the electric motors presently being used as prime movers in the industry were seen to have aged and with low power factor.

\subsection{Utility Analysis: Energy Consumption Charges}

The utility company collects energy consumption and total power demand data through metering and energy billing is on a monthly basis. For the company under study, the costs of energy consumption and total power demand during a one-year period are given in Table 1 .

Table 1. Tariff Description for Customer Classification 3 (C3)

\begin{tabular}{lccc}
\hline \multicolumn{1}{c}{ Period } & $\begin{array}{c}\text { Energy } \\
\text { Consumption Cost }\end{array}$ & $\begin{array}{c}\text { Total Power } \\
\text { Demand Cost }\end{array}$ & $\begin{array}{c}\text { Power } \\
\text { Factor }\end{array}$ \\
\hline $\begin{array}{l}\text { January 2011 - July } \\
2011\end{array}$ & $\$ 0.075 / \mathrm{kWh}$ & $\$ 2.08 / \mathrm{kVA}$ & 0.77 \\
$\begin{array}{l}\text { August 2011- } \\
\text { December 2011 }\end{array}$ & $\$ 0.088 / \mathrm{kWh}$ & $\$ 2.44 / \mathrm{kVA}$ & 0.77 \\
\hline
\end{tabular}

*Tariff for consumers (factories for manufacturing goods) with $\mathrm{HV}$ Maximum Demand (11/33kV)

0.77 is the minimum power factor on the name plate of one of the electric motors presently being used in this particular industry and is assumed for all the motors in the company.

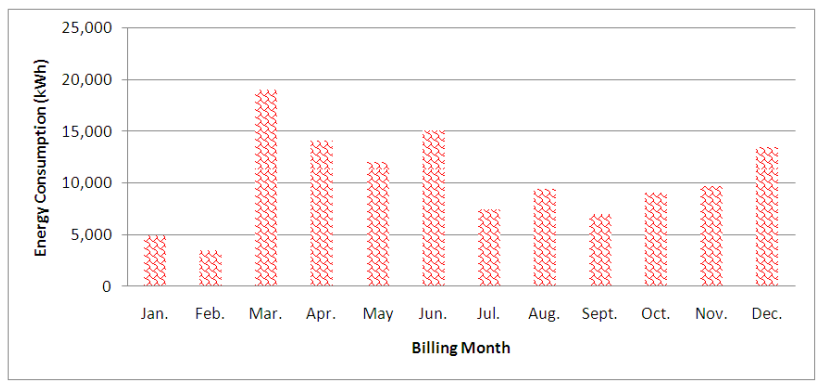

Figure 1. 2011 Monthly Electricity Consumption
The variation of energy consumption and pattern of power demand are shown in Figure 1 and Figure 2 respectively, the total energy consumption is $125,181 \mathrm{kWh}$, the highest demand which occurred in the month of July is $175 \mathrm{kVA}$ and the average demand is $150 \mathrm{kVA}$ each month. Thus using the values in Table 1, the total amount of energy and power demand charged is obtained as $\$ 10,293.93$ and $\$ 4,013.56$, totaling $\$ 14,307.49$ for the year under review.

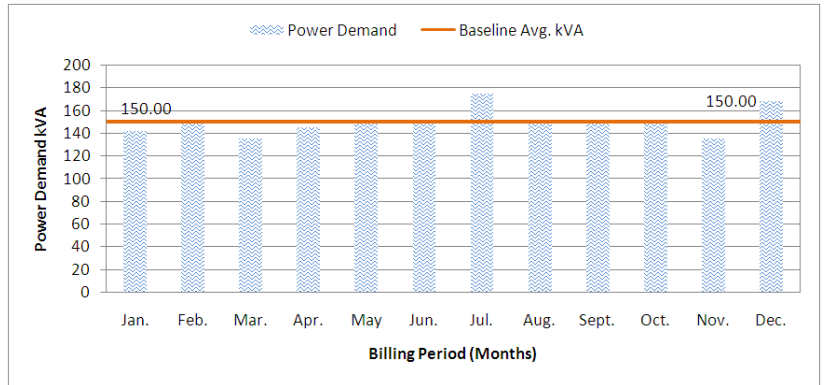

Figure 2. 2011 Monthly Total Power demand showing Baseline Average information

\subsection{Baseline Cost on Electricity}

The baseline cost is the cost per unit of energy consumed. The company has installed a 200kVA generating set, which serves as an alternative to electricity provided by the utility. The company also utilizes fossil fuel in form of diesel to power the 200kVA generating set. Total volume of fuel consumed in 2011 is 33,415 litres at a total cost of $\$ 30,255.53$. This means the company spent on diesel $\$ 0.91 /$ litre.

\subsection{Energy Management Opportunities}

A few derivable energy saving opportunities in industries have been earlier studied [39-42]. The company has a number of heavy process machines installed; these machines are responsible for its high energy consumption. Several energy management opportunities have been identified for these machines and are discussed under the following considerations: current practice and observation, recommended action and anticipated savings[43].

\subsubsection{Belt Drives on Electric Motors}

The company presently has installed standard V-belt motors used to transmit power and this result in unnecessary loss of energy. There are ten machines that run on electric motors, and the capacity of these electric motors adds up to 166.37HP.Inefficient drive belts on large motors should be replaced with energy efficient $\operatorname{cog}$ belts.

\subsubsection{Energy Consumption Data Monitoring}

The energy bills reveal that the monthly power (kVA) demand on electricity is less than the present size of $200 \mathrm{kVA}$ generating set being used by the company. This demand varied between January and May, remaining constant for two months but spiked in July, dipping slightly in August then stayed constant for the 3 months preceding November. At present the average billed demand is $150 \mathrm{kVA}$. 
This is lower than values in July and December 2011 as shown in Figure 2. With proper energy management scheme in place, a manufacturing plant may be able to reduce its excess demand costs by about $15 \%$ [43].Electrical energy demand should be monitored to reduce peak demand; since the utility company charges for the peak demand in either $k W$ or $k V A$.

\subsubsection{Turning off Equipment When not in Use}

Adopting energy efficiency and implementing conservation measures can result in significant energy savings. Some companies leave heavy energy consuming equipment $\mathrm{ON}$ particularly during breaks, when they are not in use. Each motor left ON, no matter how small, results in a large amount of wasted energy when considered over a long period. This particular analysis considered savings that could be made if machines and equipment are switched off when not in use.

\subsubsection{Light Retrofitting}

The company operates two 10-hour shifts per day, 313 days per year for a total operating time of 6,260 hours/year. The relationship between electric lamps, energy consumption and the benefits of reducing electricity consumption through the replacement of inefficient lamps with energy saving lamps have been studied by a number of authors[44-45].

Considering the energy wastage due to the use of inefficient light bulbs, the industry is presently lit with sixteen (16) 18W, Sixty-four (64) 36W Fluorescent lamps, fourteen (14) units of $40 \mathrm{~W}$ and sixty-six (66) of $60 \mathrm{~W}$ incandescent bulbs.

\subsubsection{Power Factor Correction}

Power factor correction is a highly effective means of increasing energy efficiency and reducing energy costs. This effective utilization of power allows for an increase in efficiency, as power consumption is reduced, power factor correction increases power quality, which is beneficial to the equipment itself and to the environment by reducing the amount of pollutants that are emitted into the atmosphere [46].

In this industry, most of the electric motors presently being used are ageing and have low power factor. The least power factor of 0.77 observed on one of the motors is used as the present power factor of the company for the purpose of analysis. These electric motors have also being aged with low power factor. From the monthly electricity bills, this company pays for both the real load and inductive loads. It is obvious that the company expends a lot on the inductive load resulting from the low power factor. Purchasing and installing banks of capacitors in parallel with the load or providing a matched capacitor to each motor will help offset their reactive power consumption and thus lower the energy drawn by these motors[47].

An overall average apparent power of the company is $150 \mathrm{kVA}$ considering all equipment and appliances in the company. This value is seen to be lower than the value of the apparent power of only electric motors, as could be inferred from the operations of the company, not all the equipment running on electric motors were switched on at the same time when the monthly apparent powers were been measured and recorded.

In this study considering altogether, equipment running on motors and assuming that the company may want to run all the equipment at the same time, the total real load gives $124.115 \mathrm{~kW}$; this means that all the motors are all switched On, the apparent and reactive power of the load at the selected power factor of 0.77 are $161 \mathrm{kVA}$ and $102.85 \mathrm{kVAr}$ respectively.

\section{Result \& Discussion}

\subsection{Baseline Cost of Energy (Electricity \& Diesel Consumption) and Power Demand}

The baseline costs of consumption which are based on charges due to consumption are shown in Table 2. This shows that the total cost that can be avoided over the total consumption are the unit cost of energy that can also be saved.

Table 2. The values of the baseline cost

\begin{tabular}{lcc}
\hline Description of the baseline cost & Amount/Value & Unit \\
\hline Energy consumption & 0.08 & $\$ / \mathrm{kWh}$ \\
Diesel consumption & 0.91 & $\$ /$ litres \\
Real Power & 2.90 & $\$ / \mathrm{kW}$ \\
Apparent Power & 2.23 & $\$ / \mathrm{kVA}$ \\
Reactive Power & 2.40 & $\$ / \mathrm{kVAr}$ \\
\hline
\end{tabular}

\subsection{Utility Balance}

The pie chart in Figure 3 shows the utility cost comparison for both electricity supplied by the utility and diesel purchased by the company. From Figure 4, it is obvious that the company consumption and expenditure on diesel exceeds that of electricity. The company relies majorly on self-generation to power its equipment, $68 \%$ of its energy cost is spent on diesel consumption while the rest is taken up by the utility. The reason for this is not farfetched, as regular supply of electricity by the utility company is not assured. This is the reason why many manufacturing companies in Nigeria depend on generating sets to meet their electricity requirement.

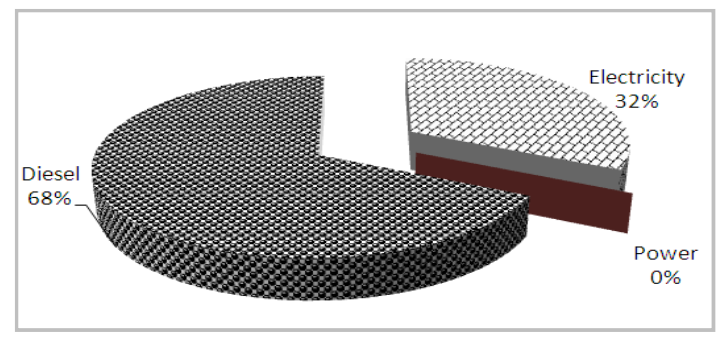

Figure 3.Utility Cost Comparison 


\subsection{Baseline Setup}

Figure 4 represents the monthly diesel consumption throughout the year 2011. The consumption is highest in the month of November and March, with the lowest in the month of August and the average consumption of 2,785 litres. The spike in the month of November could be attributed to incessant power failure, necessitating the use of generator to meet up with production throughput and deadline.

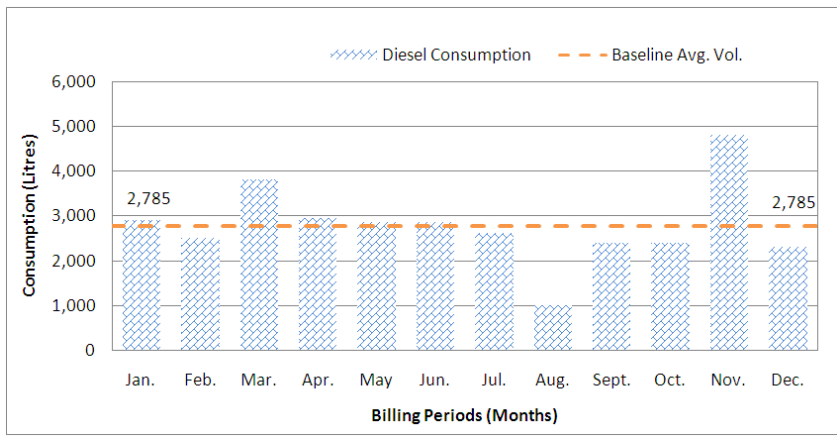

Figure 4. Diesel Consumption of 2011

Figure 5, represents the cost of running the operations of the company on diesel alone. The month of November had the highest expenditure of $\$ 4,230.00$ proportional to the volume of diesel consumed. The average monthly diesel consumption cost is $\$ 2521.29$ as shown in Figure 5 .

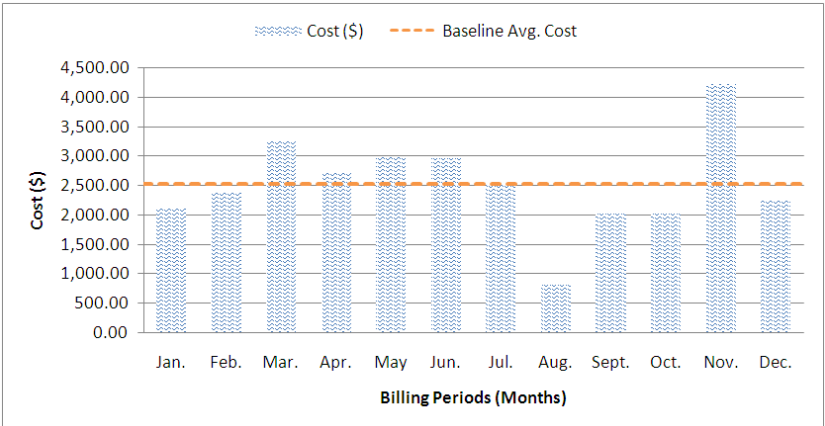

Figure 5. Diesel Consumption cost of 2011

\section{Recommendations}

To reduce losses in the form of slippage, energy used to flex the belt as it goes around pulleys, and stretching and compression of the belt, the V-belts are recommended to be replaced with energy efficient $\operatorname{cog}$ belts. These belts slip less and can bend more easily than standard V-belts.

According to [48], peaks in demand are caused by a number of different factors. Also [43] states that the two most important being the starting of large motors and starting of many motors of any size in a single 15 minute period. Electric motors can draw between 5 and 7 times their full load currents during start-ups. These current spikes will last until the motor has reached nearly full operating speed. For fully loaded motors this is typically between 30 seconds and 2 minutes. As recommended by [ 43 , 48], the starting of small motors be staggered and large motors be electronically controlled. This will slowly increase, or ramp, the current to its operating level. The reduction in the demand spike from the implementation of the soft start devices is nearly $100 \%$. All machinery should be shut down when not in use.

Energy efficient lamps are recommended for all of the company's lighting fixtures. Fluorescent lamps in $2 \mathrm{ft}$ and $4 \mathrm{ft}$ fixtures and incandescent bulbs should be replaced with energy saving lamps at a rated average of $26 \mathrm{~W}$ each. The choice of this replacement will help improve the illumination of the working areas to ensure better job performance and service. This is shown in Table 3.

It is recommended that the company should consider installing bank of capacitors in order to raise the power factor to a figure near unity so as to reduce the cost on apparent power charged by the electricity supplier. The installation of a bank of capacitors and high efficiency motors, drives, transmission, bearing and regular maintenance and lubrication will help to reduce the kVA demand while maintaining real power consumption $(\mathrm{kW}$ demand) and keep the efficiency at maximum level [49-51]. The simulated present and proposed (optimized) apparent and reactive powers are as shown in Figure 6.

This paper has described five energy management opportunities that could be adopted and implemented to achieve savings in both energy and cost in a medium scale printing company in Lagos, Nigeria. The summary of the recommendations, savings and the percentage contribution of each of the opportunities are presented in Table 4.

Table 3. The quantity and capacities of light bulbs (present and proposed) in the industry

\begin{tabular}{lccc}
\hline \multirow{2}{*}{ Quantity } & \multicolumn{3}{c}{ Lamp Type and Capacity (W) } \\
\cline { 2 - 4 } & Conventional Fluorescent Tubes & Incandescent Lamps & Compact Fluorescent Lamps (CFLs) \\
\hline 16 & $18 \mathrm{~W}$ & & $26 \mathrm{~W}$ \\
64 & $36 \mathrm{~W}$ & $40 \mathrm{~W}$ & $26 \mathrm{~W}$ \\
14 & & $60 \mathrm{~W}$ & $26 \mathrm{~W}$ \\
66 & & $4520 \mathrm{~W}$ & $26 \mathrm{~W}$ \\
Sub -Total & $2592 \mathrm{~W}$ & & $4160 \mathrm{~W}$ \\
\hline Total & $7112 \mathrm{~W}$ \\
\hline
\end{tabular}


Table 4.Summary of Assessment Recommendations

\begin{tabular}{clcccc}
\hline \multirow{2}{*}{ S/No } & \multirow{2}{*}{ DESCRIPTION } & \multicolumn{3}{c}{ ANNUAL SAVINGS } \\
\cline { 3 - 6 } & & $\begin{array}{c}\text { ENERGY } \\
\text { KWh/yr }\end{array}$ & $\begin{array}{c}\text { POWER } \\
\mathbf{k W} / \mathbf{y r}, \mathbf{k V A} \text { and } \mathbf{k V A r} / \mathbf{y r}\end{array}$ & $\begin{array}{c}\text { COST } \\
\mathbf{\$} / \mathbf{y r}\end{array}$ & $\begin{array}{c}\text { POTENTIAL } \\
\mathbf{\%}\end{array}$ \\
\hline 1 & Belts drives on motors & $13,621.00$ & $2.18 \mathrm{~kW}$ & $1,196.35$ & 19 \\
2 & Energy consumption monitoring & - & $22.5 \mathrm{kVA}$ & 781.87 & 13 \\
3 & Turning off equipment when not in use & $6,810.50$ & -- & 560.16 & 9 \\
4 & Light retrofitting & $22,099.36$ & $4.707 \mathrm{~kW}$ & $1,242.54$ & 20 \\
5 & Power factor correction & & $85.165 \mathrm{kVAr}$ & $2,450.26$ & 39 \\
\hline TOTAL & & $42,530.5$ & & $6,231.18$ & 100 \\
\hline
\end{tabular}

\section{Annual Cost Savings upon the Implementation of the Energy Management Opportunities}

According to [43] V-belts are about $92 \%$ efficient, while cog belts for both large and small drives show gains in efficiency from $2 \%$ to $5 \%$ and conservative values for gains in efficiency range from $1 \%$ to $3 \%$. For this calculation an average conservative value of $2 \%$ is used and recommended. The annual energy saving obtained from the product of the power demand on motors, annual operating time of $6260 \mathrm{hrs} / \mathrm{year}$, average load factor of 0.7 and the average conservative value of $2 \%$ is $13,621 \mathrm{kWh}$, consumption saving is $\$ 1,120.33$, demand saving is $\$ 76.03$ and total annual cost savings with the implementation of this measure is $\$ 1,196.35$.

It is anticipated that with careful control of demand, the average demand could be reduced by $15 \%$. The average demand for 2011 is $150 \mathrm{kVA}$ and the average charge for each $\mathrm{kVA}$ on peak demand is $\$ 2.90$, the total annual savings is estimated at $\$ 781.87$.

The energy savings by shutting or switching off equipment when not in use calculated from the product of power demand on motors, annual hours of unnecessary idling ( $2 \mathrm{hrs}$ per day for 313 days that the industry works in the year), motor efficiency and idling load value of $10 \%$ is found to be $6,810.50 \mathrm{kWh} / \mathrm{yr}$ and the total saving is $\$ 560.16$.

If all fluorescent lamps and incandescent bulbs are replaced with high quality energy efficient lamps, the anticipated annual savings would be $\$ 1,242.54$.

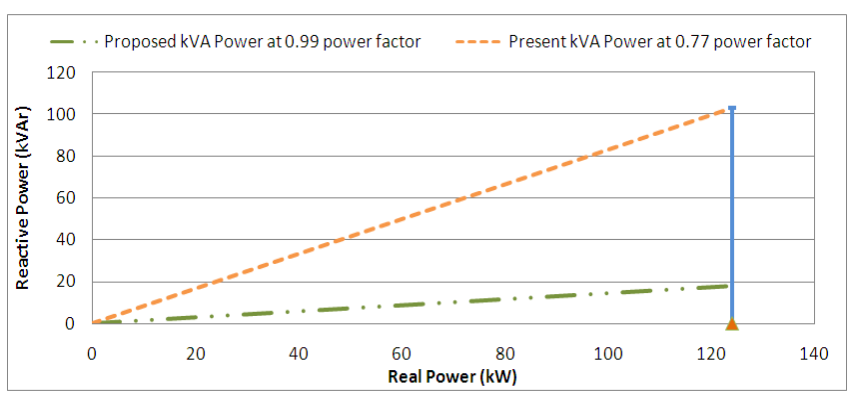

Figure 6. Present and proposed (optimized) power factor correction and capacitor bank
The saving from implementing power factor correctionto reduce inductive load in the electric motors is the difference between the present and proposed reactive power. The reactive power saving is $85.165 \mathrm{kVAr}$ which also stands for the size of the capacitor that would be installed to make the power factor close to unity and a total annual saving of $\$ 2,450.26$ as shown in Figure 6 .

\section{Conclusion}

Several opportunities for energy savings have been identified with regards to the current practice within the medium scale manufacturing company to enhance productivity. Energy management opportunities identified include; replacing inefficient drive belt on large motors with energy efficient $\operatorname{cog}$ belts, monitoring electrical loads to reduce peak demand, turning off equipment when not in use, replacing inefficient lamps with energy-saving lamps and installing banks of capacitors to increase power factor of the motors from 0.77 to 0.99 . These energy efficiency measures have been suggested to bring about anticipated energy savings when the recommendations highlighted are implemented.

Implementation of these opportunities will save the company on a continuous basis an estimated sum of Six Thousand, Two Hundred and Thirty-One (USD), and Eighteen Cent $(\$ 6,231.18)$ annually, this is about $14 \%$ of the total energy cost. This money saved will always be available as the benefit or profit derived from energy savings. It should be noted that the cost of implementing these measures has not been included in the analysis.

Many other opportunities are available and when identified, can help save part of money expended on energy, but these few have been identified based on the data gathered during the preliminary and comprehensive audits.

\section{References}

[1] M. Y. Han, G. Q. Chen, L. Shao, J. S. Li, A. Alsaedi, B. Ahmad, S. Guo, Embodied energy consumption of building construction engineering: Case study in E-town, Beijing, Energy and Buildings 64 (2013) 62-67

[2] L. Zhao, J. Zhang, R. Liang, Development of energy monitoring system for large public buildings, Energy and Buildings, 66 (2013) 41-48. 
[3] R. Budin Sc. \&A. Mihelić-Bogdanić Sc. Reducing Energy Supply In The Drying Process, Energy Engineering, 108:2, 2011, 6-16

[4] J. O'Donnell, M. Keane, E. Morrissey, V. Bazjanac, Scenario modelling: A holistic environmental and energy management method for building operation optimisation, Energy and Buildings 62 (2013) 146-157

[5] S. Ezzeldin, S. J., Rees, The potential for office buildings with mixed-mode ventilation and low energy cooling systems in arid climates, Energy and Buildings 65 (2013) 368-381

[6] M. S. Adaramola, S. S. Paul, S. O. Oyedepo, Assessment of electricity generation and energy cost of wind energy conversion systems in north-central Nigeria. Energy Conversion and Management 52 (2011) 3363-3368

[7] J. Laurijssen, A. Faaij, Worrell E., Energy conversion strategies in the European paper industry - A case study in three countries. Applied Energy. 98: 2012, 102-113

[8] A. Polycarpou, Development and Investigation of a Proposed Voltage Sag Index International Journal of Energy Optimization and Engineering, 1(1), 2012, 72-91,

[9] D. Velazquez, R. Gonzalez-Falcon, L. Perez-Lombard, L. M. Gallego, I. Monedero, F. Biscarri, Development of an energy management system for a naphtha reforming plant: A data mining approach. Energy Conversion and Management 67 (2013) 217-225

[10] G. BoroumandJazi, B. Rismanchi, R. Saidur, Technical characteristic analysis of wind energy conversion systems for sustainable development. Energy Conversion and Management 69 (2013) 87-94

[11] M. AghaAlikhani, H. Kazemi-Poshtmasari, F. Habibzadeh, Energy use pattern in rice production: A case study from Mazandaran province, Iran. Energy Conversion and Management 69 (2013) 157-162

[12] F. K. Ariyo, M. O. Omoigui, Investigation of Nigerian $330 \mathrm{kV}$ Electrical Network with Distributed Generation Penetration-Part I: Basic Analyses. International Journal of Energy and Power Engineering. Vol. 1, No. 1, 2012, pp1-19

[13] Energy Commission of Nigeria, ECN, Energy Wastages and Potential Savings Through Energy Efficiency Programmes, Energy Commission of Nigeria: (ECN); Entrenching Energy Efficiency And Conservation Into The Nation's Energy Development Strategies. Energy Commission of Nigeria, Abuja, Nigeria. (2009)

[14] Y. S. Akil, H. Miyauchi, Seasonal Peak Electricity Demand Characteristics: Japan Case Study. International Journal of Energy and Power Engineering, Vol. 2, No. 3, 2013, pp. 136-142

[15] A. S. Sambo, B. Garba, I. H. Zarma, M. M. Gaji, Electricity Generation and Present Challenges in the Nigerian Power Sector. Journal of Energy \& Power Engineering. 6(7), 2012, pp 1060-1064

[16] F. Shama, G. H. Roshani, S. Roshani, A. Ahmad, S. Karami, A Comparative Study on a Built Sun Tracker and Fixed Converter Panels. International Journal of Energy Optimization and Engineering, 1(4), 2012, 56-69.

[17] R. Karoli, (2012). The Fossil-Fuels and Global Warming.Journal of Energy \& Power Engineering. 6(4), 2012
[18] T. O. Asaolu, and P. O. Oladele, Public Enterprises and Privatisation Policy: The Nigerian Experience in Nigerian economy: Essays on Economic Development ed. (Feridun and Akindele), Munich Personal RePEc Archive, MPRA: $2006,293-394$.

[19] K. A. Obasan, and O. A. Adediran, The Role of Industrial Sector in the Economic Development of Nigeria. Journal of Management and Society, 1(2), 2010, pp. 09-16.

[20] M. Barrett, R. Lowe, T. Oreszczyn, P. Steadman, How to support growth with less energy. Energy Policy 36(12):2008, 4592-9.

[21] R. Madlener, B. Alcott, Energy rebound and economic growth: a review of the main issues and research needs. Energy 34(3):2009, 370-6

[22] C. Yuan, S. Liu, N. Xie, The impact on Chinese economic growth and energy consumption of the Global Financial Crisis: an input-output analysis. Energy. 35(4):2010, 1805-12.

[23] D. LindenbergerR. Kümmel, Energy and the state of nations. Energy. 36(10):2011, 6010-8.

[24] E. O. George, and J. E. Oseni, The Relationship Between Electricity Power And Unemployment Rates In Nigeria, Australian Journal of Business and Management Research 2(2) 2012, pp 10-19.

[25] H. Lund, F. Hvelplund, The economic crisis and sustainable development: The design of job creation strategies by use of concrete institutional economics. Energy. 43: 2012, 192-200

[26] D. P. Mehta, Ph.D., Impacts of the Save Energy Now (SEN) Program, Energy Engineering, 107:6, 2010, 43-59

[27] S. Lee, M. Teng, K. Fan, K. Yang, R. S. Horng, Application of an energy management system in combination with FMCS to high energy consuming IT industries of Taiwan. Energy Conversion and Management 52 (2011) 3060-3070

[28] G. C. Bakos, A. Sismanis, Modelling of small scale central heating installation using artificial neural networks aiming at low electric energy consumption, Energy and Buildings 62 (2013) 126-132

[29] K. N. Finney, Q. Chen, V. N. Sharifi, J. Swithenbank, A. Nolan, S. White, S. Ogden, Developments to an existing city-wide district energy network: Part II - Analysis of environmental and economic impacts. International Journal of Energy Conversion and Management, 62 :2012, 176 184

[30] N. Lior, Sustainable energy development: The present (2011) situation and possible paths to the future. Energy. 43: 2012, 174-191

[31] F. Bagheri, V., Mokarizadeh, M., Jabbar, Developing energy performance label for office buildings in Iran, Energy and Buildings, 61 (2013) 116-124.

[32] M. Bojic, K. Johannes, F. Kuznik, Optimizing energy and environmental performance of passive Trombe Wall, Energy and Buildings 70(2014) 229-286.

[33] F. R. Pazheri, N. H. Malik, A. A. Alrainy, S. Ottukulotk, M. F. Othman, E. A. Al-Ammar, I. T. P. Ahamed, Use of Renewable Energy Sources in Saudi Arabia through Smart Grid. Journal of Energy \& Power Engineering. 6(7), 2012, pp 1071-1077. 
[34] E. M. Akpabio and N. S. Akpan, Power supply and environmental sustainability in the University of Uyo: An agenda for full-blown research in Nigeria, Journal of African Studies and Development Vol. 2(6), 2010, pp. 132143.

[35] T. Ahmed, K. M. Muttaqi, A. P. Agalgaonkar, Climate change impacts on electricity demand in the State of New South Wales, Australia. Applied Energy. 98: 2012, 376-383

[36] Y. Choi, N. Zhang, P. Zhou, Efficiency and abatement costs of energy-related $\mathrm{CO}_{2}$ emissions in China: A slacks-based efficiency measure. Applied Energy. 98: 2012, 198-208

[37] H. Romero, J. J. Ambriz, J. N. Ortiz \&J. W. Sheffield, Joint Mexico/USA Energy Audits: A Case Study, Energy Engineering, 96:6, 1999, 17-28

[38] E. Maleviti, The Development of a Theoretical Model for Optimizing Energy Consumption in Buildings. International Journal of Energy Optimization and Engineering, 1(4), 2012, $1-14$.

[39] S. Wolf \&C. Howell, Newly Emerging Resource Efficiency Manager Programs, Energy Engineering, 94:6, 1997, 61-72

[40] F. Al-Ragom, CEM \&D. AlNakib CLEP, Retrofitting Domestically Used Incandescent Lamps with Compact Fluorescent Program, Energy Engineering, 103:2, 2006, 1324

[41] K. Bhattacharjee, CEM and BEP and CMVP, Energy Conservation Opportunities in Industrial Waste Heat Recovery Systems, Energy Engineering, 107:6, 2010, 7-13

[42] C. Cárdenas-LailhacarandL. Latorre Power Factor Correction: A New Industrial Energy Management Program Setup, Energy Engineering, 104:4, 2007, 21-41
[43] M. R. Muller and K. Papadaratsakis, Self-Assessment Workbook for Small Manufacturers, Ver. 2.0, October 2003, pp. 1-104. Retrieved on June 12, 2012 from iac.rutgers.edu/redirect.php?rf=selfassessment

[44] J. Stein, Four Under-utilized Opportunities, Energy Engineering, 95:2, 1998, 44-53

[45] B. F. Sule, K. R. Ajao\&H. A. Ajimotokan, A Survey of Use of Electric Lamps and Energy Consumption in Residential Buildings in Selected Estates in Ilorin, Nigeria, Energy Engineering, 108:2, 2011, 57-68

[46] F. Napoles-Rivera, M. Serna-Gonzalez, A. Bin-Mahfouz, A. Jimenez-Gutierrez, M. M. El-Halwagi, J. M. Ponce-Ortega, Simultaneous optimization of energy management, biocide dosing and maintenance scheduling of thermally integrated facilities. Energy Conversion and Management 68 (2013) 177-192

[47] S. Ilckovic, S. Mujovic, J. Radovic, A Case Study of Survey of the impact of the Inductive Loads on Power Quality. Journal of Energy \& Power Engineering. 6(10), 2012, pp 1706-1713

[48] N. Elliott, R. Papar, P. Saxon, V. Tutterow, "Building Energy Efficiency into Fan Systems," Plant Engineering. October 2000. 54.10: 2000, 53-58.

[49] O. Adegbenro,.Challenges and Prospects of Energy Efficiency and Conservation.Journal of Energy Policy, Research and Development, 1(1), 2011, pp. 104-110

[50] F. Parillo, High Efficiency Predictive Control Strategy Applied to a Power Factor Correction System. Journal of Power \& Energy Engineering. 6(11), 2012, pp 1816-1825

[51] C. Carrillo, E. Diaz-Dorado, J. Cidras, M. Siva-Ucha, A methodology for energy analysis of escalators, Energy and Buildings 61 (2013) 21-30. 